\title{
The relationship between sex and symmetry in thyroid eye disease
}

This article was published in the following Dove Press journal:

Clinical Ophthalmology

10 July 2014

Number of times this article has been viewed

\author{
Shaheen C Kavoussi' \\ Joseph N Giacometti \\ J Javier Servat ${ }^{\prime}$ \\ Flora Levin' \\ 'Department of Ophthalmology and \\ Visual Science, Yale University, \\ New Haven, CT, USA; ${ }^{2}$ Cullen \\ Eye Institute, Department of \\ Ophthalmology, Baylor College of \\ Medicine, Houston, TX, USA
}

Purpose: To examine the relationships between sex and symmetry in the context of disease activity, severity, and thyroid status in thyroid eye disease.

Methods: Retrospective chart review of 31 men and 31 women with untreated thyroid eye disease. Subjective complaints, smoking status, thyroid status, and objective findings pertinent to the clinical activity score (CAS) and "NO SPECS" classification were recorded. Overall disease asymmetry was defined as having simultaneous asymmetry of both more than one symptom and more than one external finding. Asymmetry was compared across sex and thyroid status. CAS and NO SPECS severity were compared across sex, symmetry, and thyroid status.

Results: Asymmetric appearance was reported by $58 \%$ of men and $19 \%$ of women. Asymmetric proptosis ( $>2 \mathrm{~mm}$ difference) was seen in $45 \%$ of men and $23 \%$ of women $(P=0.036)$. Overall asymmetry was seen in $55 \%$ of men and $19 \%$ of women $(P=0.017)$. Thyroid status and sex had a combined effect on symmetry, as 15 of 16 hyperthyroid females (94\%) demonstrated symmetric disease. Average NO SPECS severity was 3.5 (standard deviation [SD] 1.4) in men and 3.3 (SD 1.1) in women ( $P=0.51$ ), and was 3.8 (SD 1.4) in asymmetric patients versus 3.2 (SD 1.3) in symmetric patients $(P=0.08)$. The CAS was higher in asymmetric than symmetric patients ( 1.84 versus $0.97 ; P=0.012$ ).

Conclusion: Men demonstrated more asymmetric disease (proptosis and overall asymmetry) than women, while hyperthyroid females demonstrated more symmetry than euthyroid and hypothyroid males and females. NO SPECS severity score was unaffected by sex, thyroid status, or symmetry. Asymmetric patients demonstrated higher clinical activity scores.

Keywords: Graves' ophthalmopathy, thyroid status, clinical activity score, NO SPECS

\section{Introduction}

Thyroid eye disease (TED) is an autoimmune inflammatory disorder involving the orbital tissues. It is the most common extrathyroidal manifestation of Graves' disease but may also be associated with Hashimoto's thyroiditis. ${ }^{1-3}$ Although its pathogenesis is not completely understood, autoimmune activation of pre-adipocytic orbital fibroblasts by circulating thyroid-stimulating hormone (TSH) receptor-directed antibodies and infiltration of inflammatory cells are thought to play a central role. ${ }^{4}$ The increase in the intraorbital tissue volume results in proptosis, as well as the many clinical symptoms and signs of TED. Proptosis is a key parameter in the assessment of disease severity and activity.

Although TED is more frequent in women, the female-to-male ratio is reversed at 1:4 in severe disease..$^{5-8}$ Unilateral or asymmetric presentation is also less common than bilateral, sometimes requiring additional work-up to rule out other pathological processes. ${ }^{9}$ The aim of this study was to investigate the relationships between sex,
Correspondence: Shaheen C Kavoussi Department of Ophthalmology and Visual Science, Yale University, 40 Temple St, 3rd Floor, New Haven, CT 065I0, USA

Tel +l 2037852020

Fax + I 203785 6I23

Email shaheen.kavoussi@yale.edu 
symmetry, and thyroid status with respect to disease activity and severity.

\section{Methods}

After institutional review board approval was obtained, a retrospective chart review of all patients over 18 years of age with newly diagnosed TED and at least 6 months of follow-up at a single institution between 2007 and 2011 was performed. Mean duration of follow-up was $22.5 \pm 15.0$ months (range 5.95-69.0) and 11.2 \pm 8.3 visits (range three to 33). Patients with prior medical and surgical treatments for thyroid function were included, but those with a history of immunosuppressive or surgical intervention for TED or other orbital disease were excluded.

Signs and symptoms in four categories were recorded at each visit: subjective complaints, external findings, anterior segment abnormalities, and optic nerve compression (Table 1). Parameters were based on the clinical activity score (CAS) and "NO SPECS" classification systems. ${ }^{10,11}$ A patient with disease asymmetry was defined as having demonstrated repeatable asymmetry with regard to more than one symptom and more than one external or anterior segment finding for a duration of two or more visits at least 1 month apart at any time during the initial or follow-up period. Asymmetric patients whose signs and symptoms resolved after treatment were kept in the asymmetric category for data analysis. Asymmetric exophthalmos was defined as a difference of $>2 \mathrm{~mm}$ between eyes.

Thyroid function tests measured within 3 months of the initial visit were available in 27 men and 25 women. Hyperthyroidism was defined as having a low serum TSH level with elevated serum free thyroxine (T4) and/or triiodothyronine (T3). Euthyroidism was defined as having a normal serum TSH with normal free T4 and T3. Hypothyroidism was defined as low free T4 with elevated TSH.

Outcome measures included percentage of patients with asymmetric disease (male versus female, unpaired Student's $t$-test) and highest CAS and NO SPECS classification scores prior to treatment, which for all patients occurred at the initial \pm 3 -month follow-up visits (male versus female, symmetric versus asymmetric disease, unpaired Student's $t$-tests). These parameters were also classified by sex and thyroid status. Since treated or untreated Graves' disease was the etiology in the majority of patients, the other causes of altered thyroid status (eg, hypothyroid due to Hashimoto autoimmune thyroiditis and low substitution with levothyroxine after thyroid ablation) were not included in the statistical analysis. Since attempting to identify the effect of treatment on the aforementioned outcomes yielded insufficient sample sizes (eg, asymmetric patients managed with

Table I Asymmetry of symptoms, external findings, anterior segment abnormalities, and optic nerve compression

\begin{tabular}{|c|c|c|c|c|}
\hline & Total males, $\mathbf{n}$ & Asymmetric males, $\mathbf{n}$ & Total females, $n$ & Asymmetric females, $n$ \\
\hline \multicolumn{5}{|l|}{ Symptom } \\
\hline Pain at rest & 5 & 3 & 5 & 3 \\
\hline Pain with motility & I & I & 0 & 0 \\
\hline Surface irritation & 15 & 4 & 14 & 6 \\
\hline Blurry vision & 5 & 2 & 2 & I \\
\hline Subjective change in appearance & 29 & 18 & 15 & 6 \\
\hline \multicolumn{5}{|l|}{ External findings } \\
\hline Eyelid retraction & 21 & 11 & 25 & II \\
\hline Proptosis by Hertel exophthalmometry & 27 & 14 & 25 & 7 \\
\hline Motility restriction & 10 & 5 & 9 & 7 \\
\hline Eyelid erythema & 0 & 0 & 0 & 0 \\
\hline Eyelid edema & 3 & I & I & 0 \\
\hline \multicolumn{5}{|l|}{ Anterior segment } \\
\hline Conjunctival hyperemia & 5 & I & 8 & 3 \\
\hline Conjunctival chemosis & 2 & I & 2 & 0 \\
\hline Caruncle edema & I & 0 & 0 & 0 \\
\hline Exposure keratopathy & 4 & 0 & 5 & 3 \\
\hline \multicolumn{5}{|l|}{ Optic nerve compression } \\
\hline Visual field defect & 2 & 1 & 1 & 1 \\
\hline Relative afferent pupillary defect & I & $\mathrm{N} / \mathrm{A}$ & 1 & $N / A$ \\
\hline Color vision abnormality & 4 & 3 & 4 & 1 \\
\hline Optic nerve head abnormality & 0 & 0 & 0 & 0 \\
\hline Optic nerve OCT abnormality & 0 & 0 & 0 & 0 \\
\hline
\end{tabular}

Abbreviations: N/A, not available; OCT, optical coherence tomography 
observation versus steroids versus surgery versus steroids + surgery), this analysis was deferred for future study. Analysis of variance (ANOVA) was used to evaluate NO SPECS score by thyroid status and sex. Chi-square test was used to compare the ratios of asymmetric to symmetric patients by sex (male versus female) and thyroid status (hyperthyroid versus euthyroid and hypothyroid). Statistical significance was defined as $P<0.05$.

\section{Results}

Thirty-one male patients with a mean age of 48 years old (range 24-73) and 31 female patients with a mean age of 44 years old (range 21-65) met inclusion criteria for the study. Fifty-eight percent of men and 19\% of women reported asymmetric appearance $(P=0.001)$. Fifty-five percent of men and $26 \%$ of women demonstrated overall asymmetry, defined as more than one symptom and more than one external or anterior segment finding. This difference was statistically significant $(P=0.017)$ (Figure 1). Asymmetry was present for two or more visits at least 1 month apart during the initial evaluation period in the aforementioned patients. Patients with symmetric disease were monitored for the subsequent development of asymmetry, but this was not observed. Forty-five percent of men and $23 \%$ of women demonstrated asymmetric exophthalmos $(P=0.036)$ (Figure 2$)$. Sex did not affect the symmetry of lagophthalmos, eyelid retraction, motility restriction, eyelid erythema, eyelid edema, conjunctival chemosis, redness, or corneal or optic nerve involvement.

Sex did not affect the maximum CAS score observed during the duration of follow-up (1.48 men versus 1.16 women; $P=0.352)$. These values were largest at the initial visit, and, in some cases, an equivalent value occurred at the 3-month follow-up. Patients with overall asymmetric disease demonstrated significantly higher CAS scores compared to their symmetric counterparts ( 1.84 versus $0.97 ; P=0.012)$ (Table 2).

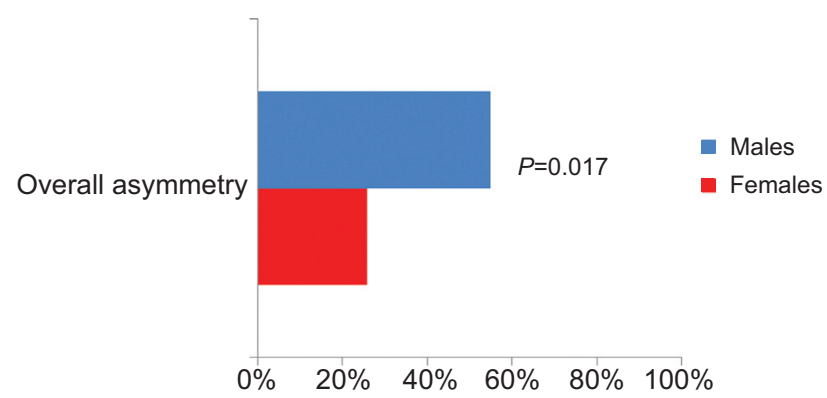

Figure I Overall asymmetry (more than one symptom and more than one external or anterior segment finding).

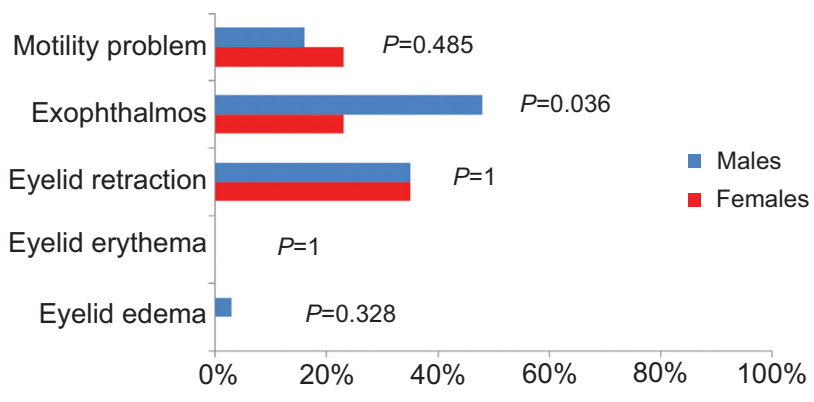

Figure 2 Percentage of patients with asymmetry of extraocular findings by sex.

There was also no significant sex difference with regard to the NO SPECS disease severity score, which averaged 3.5 (standard deviation [SD] 1.4) among men and 3.3 (SD 1.1) among women $(P=0.51)$. There was a trend toward higher NO SPECS severity scores in asymmetric patients (mean 3.8, SD 1.4, $\mathrm{n}=25$ ) compared to symmetric patients (mean 3.2, SD 1.3, $\mathrm{n}=37$ ), though the difference was not statistically significant $(P=0.08)$.

The effect of thyroid status was evaluated based on thyroid function tests taken within 3 months of the initial evaluation period when CAS and NO SPECS scores were highest. Ten men (37\%) were hyperthyroid, 13 (48\%) were euthyroid, and four (15\%) were hypothyroid (Table 3). Of the 25 women, 16 (64\%) were hyperthyroid, seven (28\%) were euthyroid, and two (8\%) were hypothyroid. There was no difference in disease severity when patients were stratified by thyroid status or sex (Table $4, P=0.82$, ANOVA).

Thyroid status, independent of sex, had no significant impact on symmetry: seven of 26 hyperthyroid patients (27\%) demonstrated asymmetry, compared to nine of 20 euthyroid patients (45\%) and two of six hypothyroid patients (33\%) ( $P=0.44$, chi-square test).

However, thyroid status and sex had a combined effect on symmetry (Table 3, Figure 3). Fifteen out of 16 hyperthyroid females presented with symmetric disease, a ratio that was significantly larger than the symmetric versus asymmetric ratio in the hyperthyroid male group, the euthyroid/ hypothyroid male group, and the euthyroid/hypothyroid female group ( $P=0.02$, chi-square test).

Table 2 Initial clinical activity score (CAS) by overall disease asymmetry

\begin{tabular}{llll}
\hline & Average initial CAS & Mean difference & $P$-value \\
\hline Males & 1.48 & 0.32 & 0.352 \\
Females & 1.16 & & \\
Symmetric & 0.97 & -0.87 & 0.012 \\
Asymmetric & 1.84 & & \\
\hline
\end{tabular}


Table 3 Symmetry by thyroid status

\begin{tabular}{|c|c|c|c|}
\hline & Hyperthyroid & Euthyroid & Hypothyroid \\
\hline Asymmetric males, $\mathrm{n}(\%)$ & $6(60)$ & $7(54)$ & I (25) \\
\hline Symmetric males, n (\%) & $4(40)$ & $6(46)$ & $3(75)$ \\
\hline Asymmetric females, $\mathrm{n}(\%)$ & $I(6)$ & $2(29)$ & I (50) \\
\hline Symmetric females, n (\%) & $15(94)$ & $5(7 I)$ & I (50) \\
\hline $\begin{array}{l}\text { Thyroid function test results } \\
\text { (within } 3 \text { months of initial evaluation) }\end{array}$ & Mean \pm SD (range) & Mean \pm SD (range) & Mean \pm SD (range) \\
\hline $\mathrm{T} 4$ total, $\mu \mathrm{g} / \mathrm{dL}$ (NR 5.0-10.6) & $12.9 \pm 7.0(5.1-32.3)$ & $7.5 \pm 1.5(5.0-10.6)$ & $4.3 \pm 0.3(4.1-4.7)$ \\
\hline Free T4, ng/dL (NR I.0-2.2) & $3.1 \pm 2.0(1.4-9.6)$ & $1.6 \pm 0.3(1.1-2.1)$ & $0.8 \pm 0.1(0.6-0.9)$ \\
\hline T3 total, ng/dL (NR 79-I49) & $245.0 \pm 176.1(107-674)$ & $1|7.| \pm 20.1(85-|4|)$ & $64.5 \pm 4.9(6 \mathrm{I}-68)$ \\
\hline $\mathrm{TSH}, \mu \mathrm{U} / \mathrm{mL}$ (NR 0.3-4.2) & $0.07 \pm 0.06(0.01-0.19)$ & $1.15 \pm 0.98(0.38-3.84)$ & $6.35 \pm 2.55(4.42-11.80)$ \\
\hline
\end{tabular}

Abbreviations: NR, normal range; SD, standard deviation; T3, triiodothyronine; T4, thyroxine; TSH, thyroid-stimulating hormone.

\section{Discussion}

Asymmetric TED accounts for approximately 5\% of unilateral exophthalmos and represents approximately $9 \%-15 \%$ of TED cases. ${ }^{12-14}$ In our study, more men than women reported asymmetry ( $58 \%$ versus 19\%), demonstrated overall asymmetry ( $55 \%$ versus $26 \%$ ), and had asymmetric exophthalmos ( $45 \%$ versus $23 \%$ ). One limitation of our study was a relatively small patient group. A larger study of 391 patients by Soroudi et al found asymmetric disease in $9 \%$ of patients ( $12 \%$ of men and $8 \%$ of women); however this difference between sexes was not statistically significant. ${ }^{14}$ Possible explanations for the increased frequency of asymmetric TED in males include the increased prevalence of smoking in males ${ }^{15}$ and poor compliance and follow-up in men, leading to a decreased likelihood of achieving biochemical control following anti-thyroid therapy for Graves' disease, ${ }^{15,16}$ and selection bias against symmetric TED due to the tendency of males to delay medical care until the advanced or more noticeable stages of disease. ${ }^{17}$ Men demonstrate decreased cosmetic impetus for medical treatment compared to females. ${ }^{18}$ Specific to TED, the noticeability of asymmetric disease may prompt men to seek evaluation, while symmetric changes are more likely to be overlooked, especially in a euthyroid male lacking systemic symptoms.

In our study, euthyroid patients demonstrated asymmetry with greatest frequency (nine of 20 patients [45\%]). Other

Table 4 "NO SPECS" severity by thyroid status and sex

\begin{tabular}{llllll}
\hline & Mean & Mean & SD & N & P-value \\
\hline Hyperthyroid males & 3.3 & 3.5 & 1.4 & 10 & 0.53 \\
Hyperthyroid females & & 3.1 & 1.5 & 16 & \\
Euthyroid males & 3.6 & 3.9 & 1.4 & 13 & 0.39 \\
Euthyroid females & & 3.3 & 1.3 & 7 & \\
Hypothyroid males & 3.3 & 3.3 & 0.5 & 4 & 0.63 \\
Hypothyroid females & & 3.5 & 0.7 & 2 & \\
\hline
\end{tabular}

Abbreviation: SD, standard deviation. reports have described similar findings. ${ }^{19-21}$ Daumerie et al presented nine patients with clinically unilateral TED, all of whom were euthyroid at the time of presentation, ${ }^{19}$ while Jang et al demonstrated greater asymmetry in euthyroid patients compared to hyperthyroid patients in a cohort of 163 patients. ${ }^{20}$ In a study of 182 patients by Eckstein et al TED patients with euthyroid or hypothyroid status demonstrated more asymmetric proptosis (difference of $1.9 \mathrm{~mm}$ versus $1.0 \mathrm{~mm}$ in hyperthyroid patients; $P=0.01$ ) and less severe orbital disease. ${ }^{21}$ Euthyroid patients in the same study were $18 \%$ more likely to demonstrate a difference in proptosis of $>3 \mathrm{~mm} .{ }^{21}$

Examining the combined effect of thyroid status and sex on symmetry at initial presentation yielded significant results. All but one of the 16 hyperthyroid females presented with symmetric disease, a ratio that was significantly higher than the hyperthyroid males and euthyroid or hypothyroid patients. Eckstein et al had complementary findings of asymmetry in the euthyroid/hypothyroid group of patients. ${ }^{21}$ Euthyroidism at the time of TED requires regular attention to thyroid function tests because thyroid dysfunction commonly develops within 1 year of TED symptoms. ${ }^{22}$

Our study did not demonstrate more severe disease (NO SPECS) or higher CAS in male patients. This contrasts other studies. ${ }^{5,15,18}$ However, in our study, patients with asymmetric disease had higher CAS and a trend toward more severe disease than their symmetric counterparts.

\section{Conclusion}

Our findings reinforce the diverse nature of TED and suggest certain trends that can be important for evaluation decisions and work-up. Our results reinforce links between male sex, euthyroid or hypothyroid orbitopathy, asymmetric disease, and increased clinical activity. TED should remain high on the differential diagnosis of asymmetric proptosis, particu- 


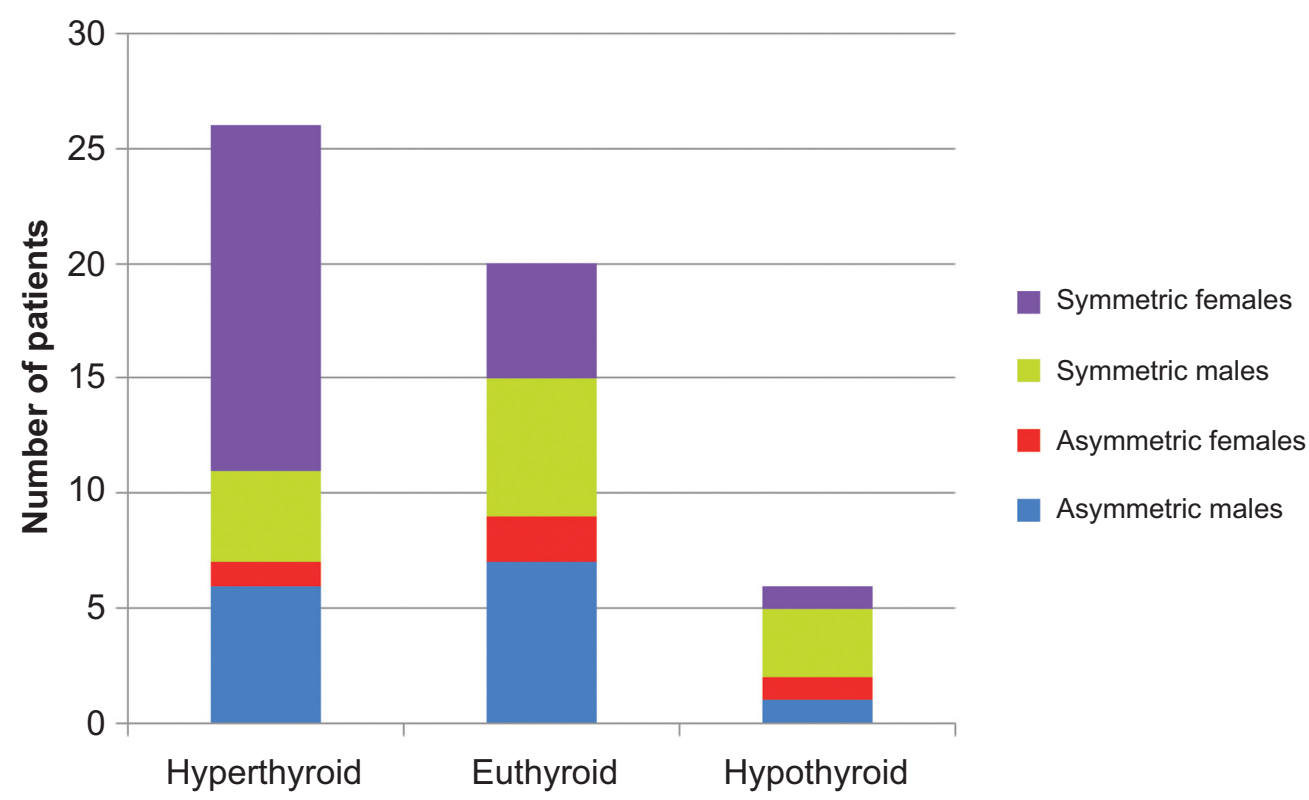

Figure 3 Symmetry by thyroid status.

larly in males. Comanagement between the ophthalmologist and endocrinologist is critical, given that these findings may result from poor compliance, decreased biochemical control, and increased prevalence of smoking in men.

The relationships between sex, symmetry, thyroid status, and CAS elucidated in this study can be helpful in describing the natural history of the disease to newly diagnosed patients. Additional avenues to be researched include the effects of race, smoking status, and treatment modality on disease symmetry and activity. Further prospective studies are indicated to continue assessment of the relationship between sex, symmetry, and disease course in TED.

\section{Acknowledgments}

This work was supported in part by an unrestricted departmental grant from Research to Prevent Blindness (RPB), Inc. This research was presented at the October 2011 ASOPRS meeting in Orlando, FL, USA.

\section{Disclosure}

The authors report no conflicts of interest in this work.

\section{References}

1. Bartalena L, Pinchera A, Marcocci C. Management of Graves' ophthalmopathy: reality and perspectives. Endocr Rev. 2000;21:168-199.

2. Perros P, Dickinson AJ. Ophthalmopathy. In: Braverman LE, Utiger RD, editors. Werner's and Ingbar's The Thyroid - A Fundamental and Clinical Text, 9th edition. Philadelphia, PA: Lippincott Williams \& Wilkins; 2005:474-487.

3. Bartley GB, Fatourechi V, Kadrmas EF, et al. Clinical features of Graves' ophthalmopathy in an incidence cohort. Am J Ophthalmol. 1996;121:284-290.
4. Bahn RS, Dutton CM, Natt N, Joba W, Spitzweg C, Heufelder AE Thyrotropin receptor expression in Graves' orbital adipose/connective tissues: potential autoantigen in Graves' ophthalmopathy. J Clin Endocrinol Metab. 1998;83:998-1002.

5. Kendler DL, Lippa J, Rootman J. The initial clinical characteristics of Graves' orbitopathy vary with age and sex. Arch Ophthal. 1993;111: 197-201.

6. Bartley GB, Fatourechi V, Kadrmas EF, et al. The incidence of Graves' ophthalmopathy in Olmsted County, Minnesota. Am J Ophthalmol. 1995;120:511-517.

7. Vanderpump MP, Tunbridge WM, French JM, et al. The incidence of thyroid disorders in the community: a twenty-year follow-up of the Whickham Survey. Clin Endocrinol (Oxf). 1995;43:55-68.

8. Wang C, Crapo LM. The epidemiology of thyroid disease and implications for screening. Endocrinol Metab Clin North Am. 1997;26: 189-218.

9. Perros P, Neoh C, Dickinson J. Thyroid eye disease. BMJ. 2009;338:b560.

10. Mourits MP, Prummel MF, Wiersinga WM, Koornneef L. Clinical activity score as a guide in the management of patients with Graves' ophthalmopathy. Clin Endocrinol (Oxf). 1997;47:9-14.

11. Werner SC. Modification of the classification of the eye changes of Graves' disease: recommendations of the Ad Hoc Committee of the American Thyroid Association. J Clin Endocrinol Metab. 1977;44:203-204.

12. Shields JA, Shields CL, Scartozzi R. Survey of 1264 patients with orbital tumors and simulating lesions: The 2002 Montgomery Lecture, part 1. Ophthalmology. 2004;111:997-1008.

13. Lumegra G, Prummel MF, Baldeschi L. Unilateral Graves orbitopathy: a case control and retrospective follow-up study. Turk Jem. 2004;8 (Suppl 1):63.

14. Soroudi AE, Goldberg RA, McCann JD. Prevalence of asymmetric exophthalmos in Graves orbitopathy. Ophthal Plast Reconstr Surg. 2004;20:224-225.

15. Manji N, Carr-Smith JD, Boelaert K, et al. Influences of age, gender, smoking, and family history on autoimmune thyroid disease phenotype. J Clin Endocrinol Metab. 2006;91:4873-4880.

16. Allahabadia A, Daykin J, Holder RL, Sheppard MC, Gough SC, Franklyn JA. Age and gender predict the outcome of treatment for Graves' hyperthyroidism. J Clin Endocrinol Metab. 2000;85:1038-1042.

17. Banks I. No man's land: men, illness, and the NHS. BMJ. 2001;323: 1058-1060. 
18. Perros P, Crombie AL, Matthews JN, Kendall-Taylor P. Age and gender influence the severity of thyroid-associated ophthalmopathy: a study of 101 patients attending a combined thyroid-eye clinic. Clin Endocrinol (Oxf). 1993;38:367-372.

19. Daumerie Ch, Duprez T, Boschi A. Long-term multidisciplinary follow-up of unilateral thyroid-associated orbitopathy. Eur J Intern Med. 2008;19:531-536.

20. Jang SY, Lee SY, Lee EJ, Yoon JS. Clinical features of thyroidassociated ophthalmopathy in clinically euthyroid Korean patients. Eye (Lond). 2012;26(9):1263-1269.
21. Eckstein AK, Lösch C, Glowacka D, et al. Euthyroid and primarily hypothyroid patients develop milder and significantly more asymmetrical Graves ophthalmopathy. Br J Ophthalmol. 2009;93:1052-1056.

22. Bartley GB, Fatourechi V, Kadrmas EF, et al. Chronology of Graves' ophthalmopathy in an incidence cohort. Am J Ophthalmol. 1996;121(4): 426-434.

\section{Publish your work in this journal}

Clinical Ophthalmology is an international, peer-reviewed journal covering all subspecialties within ophthalmology. Key topics include: Optometry; Visual science; Pharmacology and drug therapy in eye diseases; Basic Sciences; Primary and Secondary eye care; Patient Safety and Quality of Care Improvements. This journal is indexed on

\section{Dovepress}

PubMed Central and CAS, and is the official journal of The Society of Clinical Ophthalmology (SCO). The manuscript management system is completely online and includes a very quick and fair peer-review system, which is all easy to use. Visit http://www.dovepress.com/ testimonials.php to read real quotes from published authors. 